\title{
Chemical Characterization of Secondary Metabolite from the Endophytic Fungus Trichordema reecei isolated from The Twig of Syzygium aqueum
}

\author{
Ummi H. Habisukan ${ }^{1,2}$, Elfita ${ }^{3 *}$, Hary Widjajanti ${ }^{4}$, Arum Setiawan ${ }^{4}$ \\ ${ }^{1}$ Universitas Islam Negeri Raden Fatah Palembang, South Sumatra, Indonesia \\ ${ }^{2}$ Graduate School of Sciences, Faculty of Mathematics and Natural Sciences, University of Sriwijaya,. Jl. Padang Selasa No. 524, Palembang 30139, South Sumatra, Indonesia \\ ${ }^{3}$ Department of Chemistry, Faculty of Mathematics and Natural Sciences, University of Sriwijaya, Jl. Palembang Prabumulih, Indralaya, South Sumatra, 30662 Indonesia \\ ${ }^{4}$ Department of Biology, Faculty of Mathematics and Natural Sciences, University of Sriwijaya, Jl. Palembang Prabumulih, Indralaya, South Sumatra, 30662 Indonesia \\ *Corresponding author: elfita69@gmail.com
}

\begin{abstract}
Endophytic fungi are microorganisms that live in plants, without negative effects and are mutually related to hosting plants. Exploration of bioactive compounds from Endophytic fungi is easier and cheaper because they do not require a large area, a short growing time, and uncomplicated mixed compounds. Endophytic fungi are new and patent base secondary metabolites but they are not extensively characterized and investigated for the exploration of raw materials for drugs. The purpose of this study was to obtain antioxidant secondary metabolites from Endophytic fungi that live in the Syzygium aqueum medicinal plant. In this study, Endophytic fungi were isolated from $\mathrm{S}$. aqueum twigs and molecular identification. The secondary metabolites were isolated by chromatographic method and chemical structure identified by spectroscopy. Antioxidant activity was evaluated by method 1,1diphenyl-2-picryl hydrazyl (DPPH). Phylogenetic analysis showed the Endophytic fungi of S. aqueum twig have a high similarity with the Trichordema reecei twig 19MSr.B2.3. The secondary metabolites from the ethyl acetate extract of the liquid culture of the fungus were identified as (4-hydroxy-3-(4-hydroxyphenyl)-5-oxotetrahydrofuran-2-yl) methyl acetate with $\mathrm{IC}_{50}=75.13 \mu \mathrm{g} / \mathrm{mL}$. The secondary metabolites can be developed into starting molecules for potential antioxidant agents.
\end{abstract}

Keywords

Endophytic Fungus, Trichordema reecei, Syzygium aqueum, Secondary Metabolite, Antioxidant Activity

Received: 6 March 2021, Accepted: 12 June 2021

https://doi.org/10.26554/sti.2021.6.3.137-143

\section{INTRODUCTION}

The Endophytic fungi are microorganisms to colonize the host plant tissue (leaves, fruit, seeds, stems, and roots) without negative effects and having a mutually beneficial relationship. Plants have the function of protecting and providing nutrients for Endophytic fungi. In turn, Endophytic fungi will produce bioactive compounds that help the host plants improve nutritional status for growth, resistance to herbivores and diseases, and physical stress tolerance (Specian et al., 2012; Mbilu et al., 2018; El-hawary et al., 2020). Endophytic fungi are the basis of many promising natural products with varied chemical structures, higher biodiversity, and attractive bioactivity. A few researchers focused on finding secondary metabolites from Endophytic Fungi because they have been identified as a storehouse of bioactive secondary metabolites such as antibiotics, antiviral, antiprotozoal, anti-diabetic antiparasitic, anticancer, antioxidant, and immunosuppressant compounds that can be used in the agricultural, pharmaceutical and food indus- tries. These compounds are alkaloids, terpenoids, steroids, isocoumarin derivatives, lactones, quinones, flavonoids, phenols, indole derivatives, lignins, tannins, anthraquinones, xanthones, phenylpropanoids, phenolic acids, and peptides (Khan et al., 2019; Manganyi and Ateba, 2020). Natural products based on endophytic fungi are considered as one of the most relevant sources of discovery and molecular diversity for new drugs. Several studies show up to $51 \%$ of the bioactive metabolites produced from endophytic fungi have an unknown chemical structure. They can produce metabolites similar to those produced by the plant itself or new compounds produced by plants. This group of microbes represents a great potential in biotechnology for the discovery of new drugs (Cruz et al., 2020; El-hawary et al., 2020).

Syzygium aqueum, known as water guava, is native to Indonesia and Malaysia. The parts of this plant are used for traditional medicine, such as drugs for gastrointestinal disorders, bleeding, diabetes, inflammation, hypertension, antivirus, and analgesics. The use of this plant for medicine cannot be separated from 
its phytochemical composition including flavonoids, flavonoid glycosides, chromone glycosides, terpenoids, steroids, tannins, phenols, phenyl glycosides, and acylphloroglucinol derivatives These compounds have activities as antioxidants, antidiabetic, anticancer, toxicity, antiviral, antibacterial, antifungal, antiinflammatory and anthelmintic which functions in traditional medicine. This $S$. aqueum plant is rich in bioactive compounds, so it is a potential host to obtain endophytic fungi that produce bioactive compounds (Aung et al., 2020; Palanisamy et al., 2011; Sobeh et al., 2018; Osman et al., 2009).

Literature studies show that there are many bioactive components in this plant, but no research has been found on the isolation of endophytic fungi and their pure compounds from $S$. aqueum twigs. Therefore, this paper describes the isolation and identification of endophytic fungi from the twigs of $S$. aqueum, followed by the isolation, identification, and evaluation of the antioxidant activity of these secondary metabolites. In this study, it is known whether the secondary metabolites of this endophytic fungus have the potential to be developed as a source of antioxidants.

\section{EXPERIMENTAL SECTION}

\subsection{Materials}

The chemicals used such as ethanol $70 \%$, distilled $\mathrm{H}_{2} \mathrm{O}$, sodium hypochlorite (NaOCl) (Merck), growth medium for fungi: PDA and PDB (Merck), silica gel for gravity column (Merck), TLC silica gel 60 F254 from Merck (Art.5554), DPPH (SigmaAldrich), and organic solvents (Merck).

\subsection{Plant Material Collection}

The twig of S. aqueum was collected from Indralaya, Ogan Ilir Regency, South Sumatra, Indonesia. Plant identification was conducted at the Biosystematics Laboratory, Biology, FMIPA Sriwijaya University, with herbarium ID 237064.

\subsection{Isolation of Endophytic Fungal}

Isolation of endophytic isolates followed the procedure by Mbilu et al., 2018; Habisukan et al., 2021 with a few modifications. S. aqueum twig is washed under running water to remove impurities. The surface of the twigs was sterilized by immersing the plant material in $75 \%$ ethanol for 2 minutes followed by $4 \% \mathrm{NaOCl}$ for 1 minute and then rinsed twice using sterile distilled water. The plant material is allowed to dry on sterile filter paper and then cut to size $2 \times 0.5 \mathrm{~cm}$. Furthermore, three pieces were placed on a petri dish containing PDA (200 g potato, $20 \mathrm{~g}$ dextrose, and $15 \mathrm{~g}$ agar in $1000 \mathrm{~mL}$ of $\mathrm{H}_{2} \mathrm{O}$, supplemented with $100 \mathrm{mg} / \mathrm{L}$ of chloramphenicol). Colony purification was done by further subculturing the fungal colonies in PDA until pure isolates were acquired.

\subsection{Identification of Endophytic Fungal}

Identification of endophytic isolates followed the procedure by Yohandini et al., 2015 which is molecularly by comparing the similarity of sample sequences with a web-based database known as BLAST (Basic Local Alignment Search Tool).

\subsection{Cultivation of Endophytic Fungal}

Pure isolates of Endophytic fungi were cultured at 6 flasks containing $200 \mathrm{~mL}$ of PDB medium (consisting of $20 \mathrm{~g}$ dextrose monohydrate, $200 \mathrm{~g}$ potatoes, and $1 \mathrm{~L}$ (water). Six mycelia agar plugs $\left(5 \times 5 \mathrm{~mm}^{2}\right)$ were inoculated into each erlenmeyer and then incubated at room temperature under static conditions for four weeks. After the incubation was complete, the media was filtered and extracted three times using ethyl acetate. Ethyl acetate extract was evaporated with a rotary evaporator until a concentrated extract $(6.4 \mathrm{~g})$ and stored in a glass bottle (Gustianingtyas et al., 2020; Elfita et al., 2019).

\subsection{Antioxidant activity test by DPPH method}

Antioxidant activity test of ethyl acetate viscous extract using the DPPH method following the procedure by Budiono et al, 2019 with modification. The sample concentrations were prepared with variations of $200,100,50,25,12.5,6.25,0.0$ $\mu \mathrm{g} / \mathrm{mL}$, and gallic acid as a positive control. The percentage of DPPH absorption inhibition with the following formula:

$$
\% \text { Inhibition }=\frac{\text { Control Absorbance }- \text { Sample Absorbance }}{\text { Control Absorbance }} \times 100 \%
$$

2.7 Isolation and Identification of Secondary Metabolite The crude extracts were separated using column chromatography (stationary phase: silica gel) and eluted with a graded eluent (n-hexane: ethyl acetate: methanol). Eluate droplets were collected every $10 \mathrm{ml}$ in the vials and monitored by TLC analysis to group the vials into subfractions. The subfraction was identified as having secondary metabolites, then purified by column chromatography until a pure compound was obtained. The structure was identified by NMR 1D and 2D (Budiono et al., 2019).

\section{RESULTS AND DISCUSSION}

\subsection{Isolation of Endophytic Fungal}

S. aqueum twig has isolated EF labeled with B11. The molecular identification yields sequence assembly 577 bp endophytic fungus B11 is as follows:

CTCCCAAACCCCAATGTGAACGTTACCAATCTGTTG CCTCGGCGGGATTCTCTGCCCGGGGCGCGTCGCAG CCCCGGATCCCATGGCGCCCGCCGGAGGACCAACTC AAACTCTTTTTTCTCTCGGTCGCGGCTTCCGTCGCG GCTCTGTTTTACCTTTGCTCTGAGCCTTTCTCGGCG ACCCTAGCGGGCGTCTCGAAAATGAATCAAAACTTT CAACAACGGATCTCTTGGTTCTGGCATCGATGAAGA ACGCAGCGAAATGCGATAAGTAATGTGAATTGCAGA ATTCAGTGAATCATCGAATCTTTGAACGCACATTGC GCCCGCCAGTATTCTGGCGGGCATGCCTGTCCGAG CGTCATTTCAACCCTCGAACCCCTCGGGGGGGTCG GCGTTGGGGATCGGCCCCTCACCGGGCCGCCCCCG AAATACAGTGGCGGTCTCGCCGCAGCCTCTCCTGC GCAGTAGTTTGCACACTCGCACCGGGAGCGCGGCG CGGCCACAGCCGTAAAACACCCCAAACTCTGAAATG TTGACCTCGGATCAGGTAGGAATACCGGCTGAACTT 


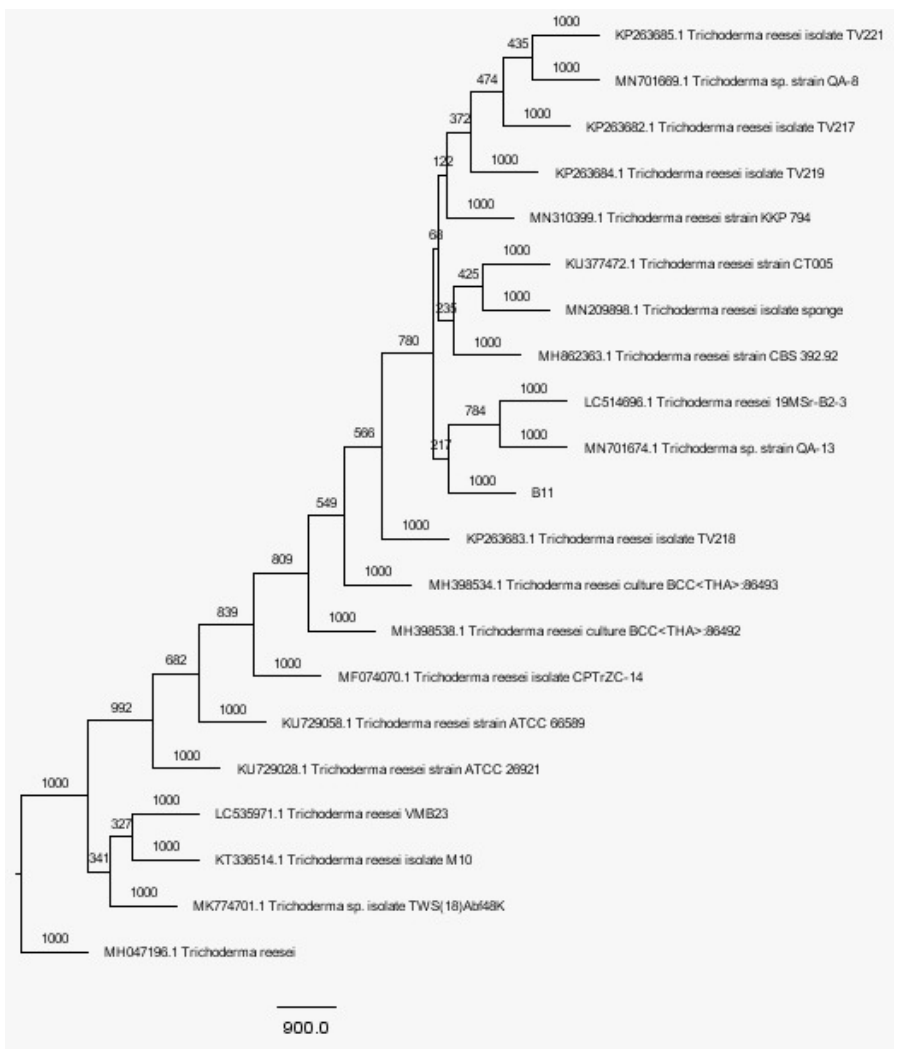

Figure 1. Phylogenetic Tree of the Endophytic Fungal B11

AAGCATA. The strain B11 has the accession number MW52 7423. The endophytic fungal B1 1 had the highest homology with Trichordema reecei twig 19MSr.B2.3. Phylogenetic analysis follows the method described shown in Figure 1.

\subsection{Isolation and Identification of Secondary Metabolite}

Separation of concentrated EtOAc extracts $3.2 \mathrm{~g}$ (silica gel: 70-230 mesh; $50 \mathrm{~g})$ obtained subfraction B $(0.9 \mathrm{~g})$ with a purple stain on TLC analysis. Purification was done by column chromatography (silica gel 70-230 mesh; $20 \mathrm{~g}$ ) with eluent n-Hexane - EtOAc (7:3 $\rightarrow$ 0:10) yielded two fractions (B1B2). The B2 fraction ( $426 \mathrm{mg}$ ) was purified again by column chromatography until compound 1 (244 mg) was obtained.

Figure 2 shows the ${ }^{1} \mathrm{H}-\mathrm{NMR}$ spectrum of the isolated compound 1. The special characteristic of the para-substituted aromatic ring in compound 1 can be identified in the H-NMR spectrum by the presence of a double pair of aromatic proton signals at $\delta \mathrm{H} 7.74$ and $8.20 \mathrm{ppm}$ each of which has a value of $\mathrm{J}=8.5 \mathrm{~Hz}$ with two integration. Another characteristic that can be identified from the C-NMR spectrum is the presence of a high-intensity carbon signal at $\delta \mathrm{C} 128.3$ and $123.9 \mathrm{ppm}$ for two carbons in the same chemical shift respectively. HMQC spectrum analysis showed that the two high-intensity carbons bind to aromatic protons equivalent at $\delta \mathrm{H} 7.74$ and $8.20 \mathrm{ppm}$ respectively. A methyl acetate-substituted cyclic lactone ringside group was identified by the presence of two carbonyl ester

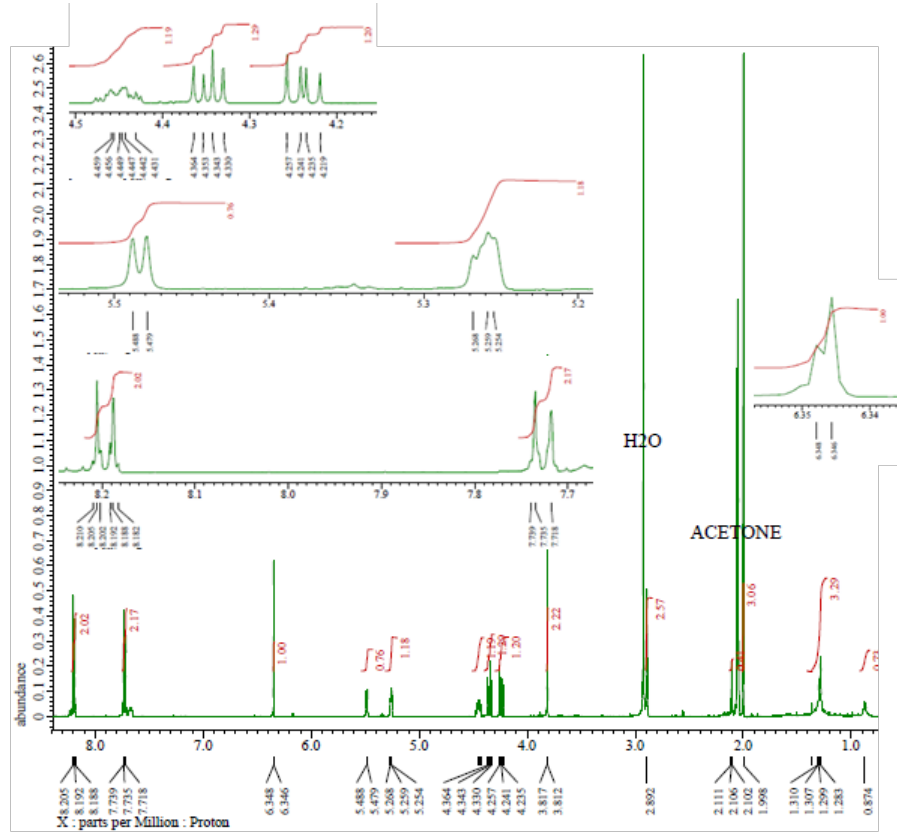

Figure 2. The ${ }^{1} \mathrm{H}-\mathrm{NMR}$ spectra of compound 1

signals at $\delta \mathrm{C} 164.7$ and $170.9 \mathrm{ppm}$ respectively and a singlet signal at $\delta \mathrm{H} 2.00 \mathrm{ppm}$ with triple integration for the methyl proton. Two multiplet proton signals at $\delta \mathrm{H} 4.35$ and 4.24 ppm are the methylene groups of the methyl ester which are strengthened by DEPT 135 and HMQG spectrum, which are bound to $\delta \mathrm{C} 63.9 \mathrm{ppm}$. The position of the phenol hydroxyl group was determined based on the ${ }^{13} \mathrm{C}$-NMR spectrum analysis. oxyaryl carbon at $\delta \mathrm{C} 150.6 \mathrm{ppm}$ while the other hydroxyl groups in the lactone ring were identified as bound to carbon $\delta \mathrm{C} 67.4 \mathrm{ppm}$.

${ }^{1} \mathrm{H}$ and ${ }^{13} \mathrm{C}$ NMR spectrum shows that the basic structure of compound 1 is a para-substituted aromatic ring of which the hydroxyl group and ester. In acetone, the number of hydroxyl groups can be seen from the proton signal that is not bound to carbon. The HMQC spectrum (Figure 3 ) shows the presence of seven single-bonded 1H-13C correlations, two correlations for aromatic rings and five correlations for ester substituents. There are two uncorrelated protons ${ }^{1} \mathrm{H}-{ }^{18} \mathrm{C}$ one bond identified as aromatic hydroxy protons $(\delta \mathrm{H} 7.68 \mathrm{ppm})$ and aliphatic hydroxyl protons $(\delta \mathrm{H} 5.48 \mathrm{ppm})$. The HMBC spectrum in Figure 4 shows that the ester group substituent is a pentacyclic lactone ring. Methine carbon at $\delta \mathrm{C} 67.4 \mathrm{ppm}$ (C-4') binds a hydroxyl group that correlates ${ }^{1} \mathrm{H}-{ }^{13} \mathrm{C}$ three bonds with signal C-3' and a methine proton which correlates two bonds with carbonyl carbon (C-5'). Methine carbon at $\delta \mathrm{C}$ $71.2 \mathrm{ppm}\left(\mathrm{C}-2^{\prime}\right)$ binds a methyl ester group is indicated by the ${ }^{1} \mathrm{H}-{ }^{13} \mathrm{C}$ correlation of two methylene proton bonds with C-2' and the triple bond correlation with C-3' and C carbonyl methyl ester.

The COSY spectrum in Figure 5 shows the aromatic protons at $\delta \mathrm{H} 7.74 \mathrm{ppm}{ }^{1} \mathrm{H}_{-}{ }^{1} \mathrm{H}$ correlated three bonds with aro- 

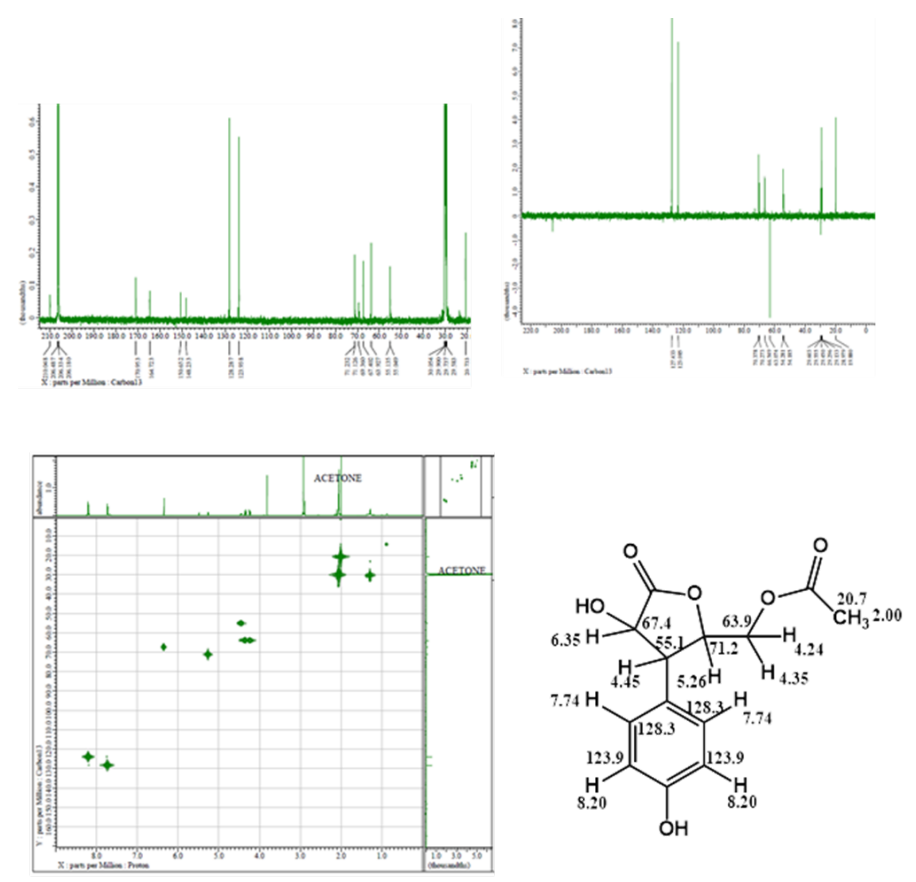

Figure 3. The ${ }^{13} \mathrm{C}-\mathrm{NMR}$ (A) DEPT 135 (B), HMQG (D)

Spectra of Compound 1 and HMQC Correlation (D)

matic protons at $\delta \mathrm{H} 8.20 \mathrm{ppm}$ and correlated long distances with four bonds with methine protons at $\delta \mathrm{H} 4.45 \mathrm{ppm}$. Furthermore, it was identified the correlation of ${ }^{1} \mathrm{H}-{ }^{1} \mathrm{H}$ three methine proton bonds at $\delta \mathrm{H} 4.45 \mathrm{ppm}$ with methine protons at $5.26 \mathrm{ppm}$. This shows the two equivalent aromatic protons are in the ortho position. These results support the proposed structure that compound 1 is a para-substituted benzene ring that is directly attached to the lactone substituent methine carbon. Compound 1 was identified as (4-hydroxy- 3(4-hydroxyphenyl)-5-oxotetra hydrofuran-2yl) methyl acetate. The molecular structure with the numbering of carbon atoms and the chemical shift placement of the carbon and protons is shown in Figure 5.

Based on a literature study, compound 1 has a different phenyls structure with Phenyls of S. aqueum and other Syzygium $s p p$. This shows that compound 1 is produced by endophytic fungi and the host does not have the gene to promote the compound. there is no genetic evolution between fungal genes and host genes in promoting their secondary metabolites.

The Trichoderma spp inhabiting healthy tissues of host plants as endophytic fungi (Elfita et al., 2014). Endophytic fungi from Trichoderma family can can produce a broad variety of bioactive compounds. Ding et al., 2019 isolated an antibacterial compound derived from isocumarin, chromone derivatives, and lichexanthone from the endophytic fungus Trichoderma harzianum isolated from the leaves of Ficus elastic. Harwoko et al., 2019 reported antifungal and cytotoxic compounds, namely Dithiodiketopiperazines produced by the endophytic fungi Trichoderma harzianum isolated from Zingiber officinale

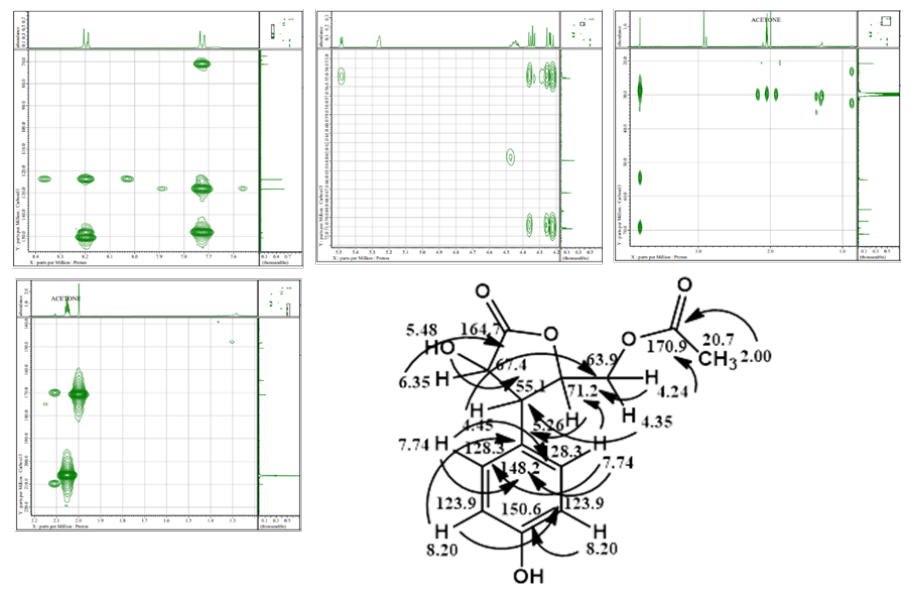

Figure 4. The HMBC spectra (A) and HMBC Correlation (B) of Compound 1

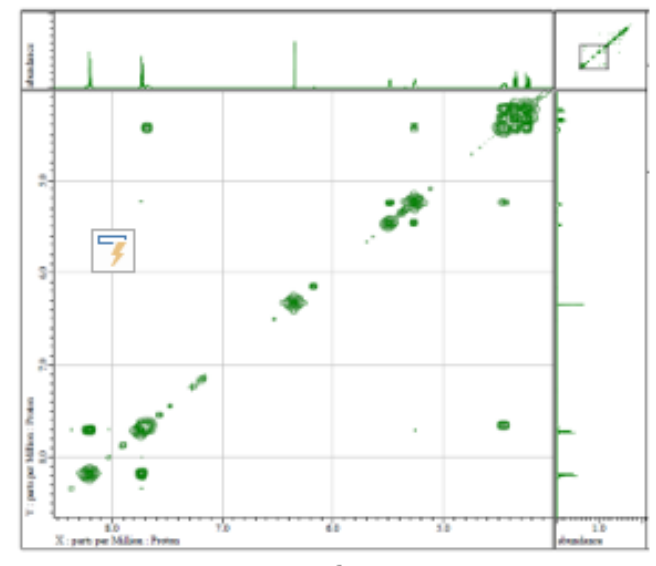

A

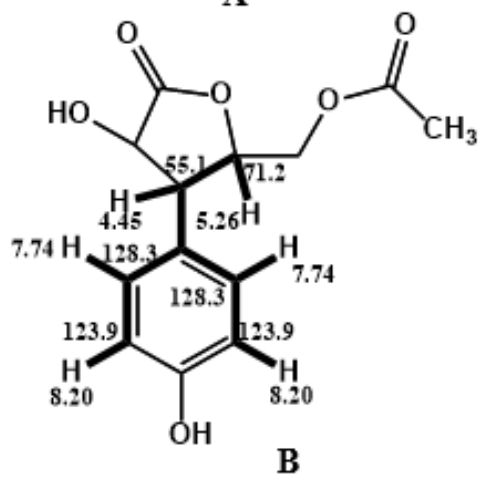

Figure 5. The COSY Spectra (A) and COSY Correlation (B) of Compound 1 
Table 1. The NMR Data of Compound 1

\begin{tabular}{ccccc}
\hline No. C & $\delta$ C ppm & $\delta$ H ppm $(\Sigma$ H. multiplicity. J (Hz)) & HMBC & COSY \\
\hline 1 & 148.2 & - & - & - \\
2 & 128.3 & $7.74(1 \mathrm{H}, \mathrm{d}, 8.5)$ & $71.2 ; 128.3 ; 148.2$ & $8.20 ; 4.45$ \\
3 & 123.9 & $8.20(1 \mathrm{H}, \mathrm{d}, 8.5)$ & $123.9 ; 148.2 ; 150.6$ & 7.74 \\
4 & 150.6 & - & - & - \\
5 & 123.9 & $8.20(1 \mathrm{H}, \mathrm{d}, 8.5)$ & $123.9 ; 148.2 ; 150.6$ & 7.74 \\
6 & 128.3 & $7.74(1 \mathrm{H}, \mathrm{d}, 8.5)$ & $71.2 ; 128.3 ; 148.2$ & 8.20 \\
2 & 71.2 & $5.26(1 \mathrm{H}, \mathrm{m})$ & $128.3 ;(150.6 \mathrm{k})$ & 4.45 \\
3 & 55.1 & $4.45(1 \mathrm{H}, \mathrm{d}, \mathrm{m})$ & 63.9 & 5.26 \\
4 & 67.4 & $6.35(1 \mathrm{H}, \mathrm{d}, \mathrm{1})$ & 164.7 & - \\
5 & 164.7 & - & - & - \\
$1 "$ & 170.9 & - & - & - \\
$2 ”$ & 20.7 & $2.00(3 \mathrm{H}, \mathrm{s})$ & 170.9 & - \\
$3 ”$ & 63.9 & $4.35(1 \mathrm{H}, \mathrm{m})$ & $55.1 ; 71.2 ; 170.9$ & - \\
& & $4.24(1 \mathrm{H}, \mathrm{m})$ & $55.1 ; 71.2 ; 170.9$ & - \\
4 '-OH & - & $5.48(1 \mathrm{H}, \mathrm{d}, 4.5)$ & 55.1 & - \\
$4-\mathrm{OH}$ & - & $7.68(1 \mathrm{H}, \mathrm{br})$ & - & \\
\hline
\end{tabular}

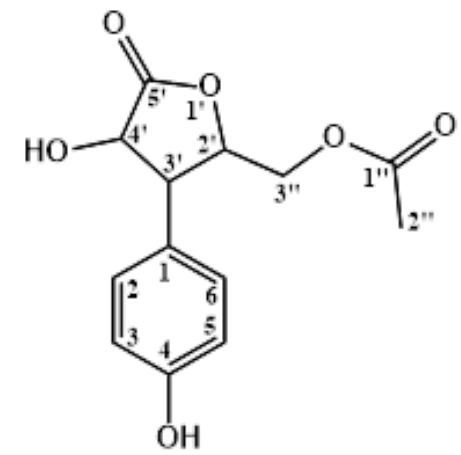

Figure 6. Compound 1 as (4-hydroxy-3-(4-hydroxyphenyl)-5oxotetrahydrofuran-2-yl)methyl acetate

(Palanisamy et al., 2011)). Besides that, taxol compounds from Trichoderma sp. isolated from Taxus chinensis (Liu et al., 2009). Five sesquiterpene compounds from Trichoderma sp. from the stem of Paeonia delavayi (Wu et al., 2011), Trichodermin compounds (4b-acetoxy-12, 13-epoxytrichothec-9-ene) from $T$. koningiopsis VM115 isolated from Vinca plants have antifungal activity (Leylaie and Zafari, 2018). This trichodermin compound is also produced by the endophytic compound Trichoderma brevicompactum isolated from Allium sativum (Shentu et al., 2014). Compound 1 has not been found in the endophytic fungus Trichoderma $s p$. so that it can complete the chemical profile of the genus.

Compound 1 has moderate antioxidant activity with a value of $\mathrm{IC}_{50}=75.13 \mu \mathrm{g} / \mathrm{mL}$, while gallic acid as a standard antioxidant has a value of IC50 $=11.45 \mu \mathrm{g} / \mathrm{mL}$. However, higher antioxidant activity can be obtained by semisynthesis of compound 1 to produce phenyl similar to gallic acid. The $\mathrm{OH}$ group in the aromatic ring of compound 1 is ortho-directing

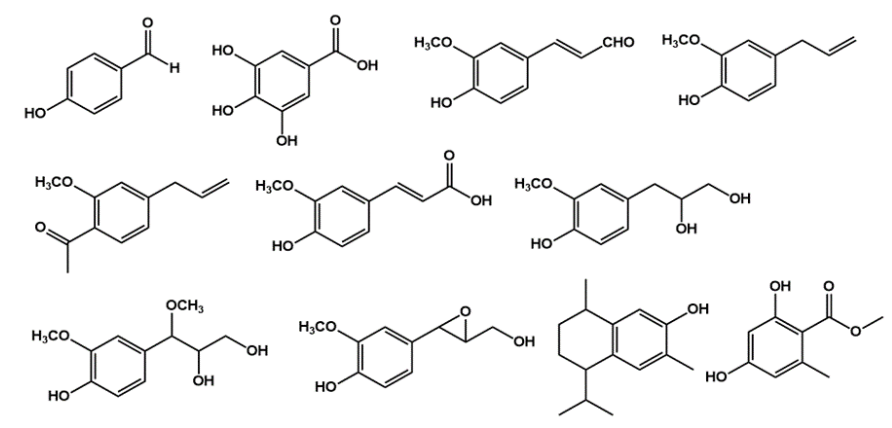

Figure 7. Phenyls of S. aqueum and other emph Syzygium spp (Aung et al., 2020)

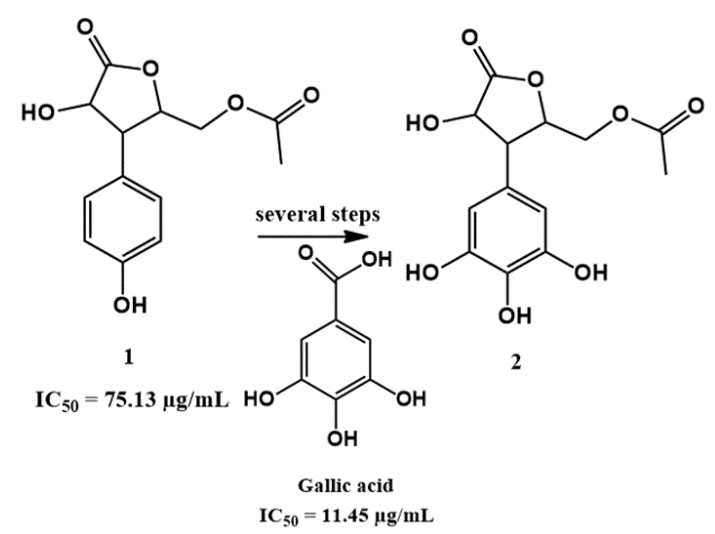

Figure 8. Estimates Semisynthesis Reaction of Compounds 1 to Produce a New Compound which is more Active with the Standard like Structure Antioxidant Gallic Acid 
so that the electrophilic reaction of Nitration $\left(2 \mathrm{~mol} \mathrm{HNO}_{3} /\right.$ $\mathrm{H}_{2} \mathrm{SO}_{4}$ ) is followed by reduction of the nitro group $(\mathrm{Fe} / \mathrm{HCl})$ will produce two amine groups on both ortho sides of the hydroxyl group.

The next step is the transformation of the amine functional group by reaction with cold nitrous acid (HONO) in $\mathrm{HCl}$ solution to yield aryldiazonium chlorides $\left(\mathrm{ArN}^{2+} \mathrm{CI}\right)$. Displacement by -OH may be prepared from diazonium salts by reaction with hot aqueous acid. This series of reactions is estimated to produce the compound (4-hydroxy-5-oxo-3- $(3,4,5$ trihydroxyphenyl) tetrahydrofuran-2-yl) methyl acetate (Figure 8) (Fessenden and Fessenden, 1982).

\section{CONCLUSIONS}

Secondary metabolites isolated from $T$. reecei different from the secondary metabolites produced by its host. Moreover, these secondary metabolites have never been found in the endophytic fungus Trichoderma family. The antioxidant activity of this compound is classified as moderate, but the production process is easier and cheaper so that it can be turned into star molecules through a semisynthetic process to produce potential antioxidant compounds.

\section{ACKNOWLEDGEMENT}

This research was funded by Daftar Isian Pelaksanaan Anggaran (DIPA) Universitas Sriwijaya, through Unggulan Profesi grants 2020, number 0009/UN9/SK.LP2M.PT/2020, September $28,2020$.

\section{REFERENCES}

Aung, E. E., A. N. Kristanti, N. S. Aminah, Y. Takaya, and R. Ramadhan (2020). Plant description, phytochemical constituents and bioactivities of Syzygium genus: A review. A Review De Gruyter Open Chemistry, 18(1); 1256-1281

Budiono, B., E. Elfita, M. Muharni, H. Yohandini, and H. Widjajanti (2019). Antioxidant activity of Syzygium samarangense L. and their endophytic fungi. Molekul, 14(1); 48-55

Cruz, J. S., C. A. da Silva, and L. Hamerski (2020). Natural Products from Endophytic Fungi Associated with Rubiaceae Species. Journal of Fungi, 6(3); 128

Ding, Z., T. Tao, L. Wang, Y. Zhao, H. Huang, D. Zhang, M. Liu, Z. Wang, and J. Han (2019). Bioprospecting of novel and bioactive metabolites from endophytic fungi isolated from rubber tree Ficus elastica leaves. Journal of Microbiology and Biotechnology, 29(5); 731-738

El-hawary, S. S., A. S. Moawad, H. S. Bahr, U. R. Abdelmohsen, and R. Mohammed (2020). Natural product diversity from the endophytic fungi of the genus Aspergillus. Royal Society of Chemistry Advances, 10(37); 22058-22079

Elfita, Munawar, Muharni, and M. A. Sudrajat (2014). Identification of new lactone derivatives isolated from Trichoderma $s p$., an endophytic fungus of brotowali (Tinaspora crispa). Hayati Journal of Biosciences, 21(1); 15-20
Elfita, E., J. E. Larasati, and H. Widjajanti (2019). Antibacterial activity of Cordyline fruticosa leaf extracts and its endophytic fungi extracts. Biodiversitas Journal of Biological Diversity, 20(12); 3804-3812

Fessenden, R. and J. Fessenden (1982). Organic Chemistry Second Edition. Boston, Massachusetts: Willard Grant Press Gustianingtyas, M., S. Herlinda, S. Suwandi, S. S. Suparman SHK, H. Hamidson, H. Hasbi, A. Setiawan, M. Verawaty, E. Elfita, and A. Arsi (2020). Toxicity of entomopathogenic fungal culture filtrate of lowland and highland soil of South Sumatra (Indonesia) against Spodoptera litura larvae. Biodiversitas (Journal of Bological Diversity), 21(5); 1839-1849

Habisukan, U., H. Widjajanti, A. Setiawan, A. Kurniawati, et al. (2021). Antioxidant and Antimicrobial Activity of Endophytyc Fungi Isolated from Syzygium aqueum Leaves. Journal of Physics: Conference Series, 1751(1); 1-8

Harwoko, H., G. Daletos, F. Stuhldreier, J. Lee, S. Wesselborg, M. Feldbrügge, W. E. Müller, R. Kalscheuer, E. Ancheeva, and P. Proksch (2019). Dithiodiketopiperazine derivatives from endophytic fungi Trichoderma harzianum and Epicoccum nigrum. Natural Product Research; 1-9

Khan, R., S. T. Q. Naqvi, N. Fatima, and S. A. Muhammad (2019). Study of antidiabetic activities of endophytic fungi isolated from plants. Pure and Applied Biology, 8(2); $1287-$ 1295

Leylaie, S. and D. Zafari (2018). Antiproliferative and antimicrobial activities of secondary metabolites and phylogenetic study of endophytic Trichoderma species from Vinca plants. Frontiers in Microbiology, 9; 1484

Liu, K., X. Ding, B. Deng, and W. Chen (2009). Isolation and characterization of endophytic taxol-producing fungi from Taxus chinensis. Journal of Industrial Microbiology and Biotechnology, 36(9); 1171

Manganyi, M. C. and C. N. Ateba (2020). Untapped Potentials of Endophytic Fungi: A Review of Novel Bioactive Compounds with Biological Applications. Microorganisms, 8(12); $1-25$

Mbilu, M., W. Wanyoike, M. Kangogo, C. Bii, M. Agnes, and C. Kihia (2018). Isolation and Characterization of Endophytic Fungi from Medicinal Plant Warburgia ugandensis. Journal of Biology, Agriculture and Healthcare, 8(12); 57-66

Osman, H., A. A. Rahim, N. M. Isa, and N. M. Bakhir (2009). Antioxidant activity and phenolic content of Paederia foetida and Syzygium aqueum. Molecules, 14(3); 970-978

Palanisamy, U. D., L. T. Ling, T. Manaharan, V. Sivapalan, T. Subramaniam, M. Helme, and T. Masilamani (2011). Standardized extract of Syzygium aqueum: a safe cosmetic ingredient. International Journal of Cosmetic Science, 33(3); 269-275

Shentu, X., X. Zhan, Z. Ma, X. Yu, and C. Zhang (2014). Antifungal activity of metabolites of the endophytic fungus Trichoderma brevicompactum from garlic. Brazilian Journal of Microbiology, 45(1); 248-254

Sobeh, M., M. F. Mahmoud, G. Petruk, S. Rezq, M. L. Ashour, 
F. S. Youssef, A. M. El-Shazly, D. M. Monti, A. B. AbdelNaim, and M. Wink (2018). Syzygium aqueum: A polyphenolrich leaf extract exhibits antioxidant, hepatoprotective, painkilling and anti-inflammatory activities in animal models. Frontiers in Pharmacology, 9(566); 1-14

Specian, V., M. H. Sarragiotto, J. A. Pamphile, and E. Clemente (2012). Chemical characterization of bioactive compounds from the endophytic fungus Diaporthe Helianthi isolated from Luehea divaricata. Brazilian Journal of Microbi- ology, 43(3); 1174-1182

Wu, S.-H., L.-X. Zhao, Y.-W. Chen, R. Huang, C.-P. Miao, and J. Wang (2011). Sesquiterpenoids from the Endophytic Fungus Trichoderma sp. PR-35 of Paeonia delavayi. Chemistry and Biodiversity, 8(9); 1717-1723

Yohandini, H., Julinar, and Muharni (2015). Isolation and phylogenetic analysis of thermophile community within Tanjung Sakti hot spring, South Sumatera, Indonesia. Hayati Journal of Biosciences, 22(3); 143-148 